\title{
The Value of Treating Opioid Use Disorder in Family Medicine: From the Patient Perspective
}

\author{
Claire Kane, BA, Catherine Leiner, BS, Chase Harless, MSW, Kathleen A. Foley, PhD, \\ E. Blake Fagan, MD, and Courtenay Gilmore Wilson, PharmD, BCACP, CPP
}

Introduction: Despite evidence demonstrating that medications for opioid use disorder (OUD) reduce morbidity and mortality, the majority of patients do not receive treatment. The National Academies of Science call for more research exploring the patient's perspective of treatment modalities to increase access to individualized, patient-centered care. We aim to build on existing literature by describing patient experiences treated for OUD in a rural family medicine setting.

Methods: We employed a convenience sampling methodology to complete brief, structured interviews with thematic data analysis for 30 of 57 eligible patients receiving office-based opioid treatment (OBOT) in the primary care setting.

Results: Participants' experiences with OBOT were generally positive and shaped by societal structures and institutions, their life before treatment, their treatment history, and the kind of care they received in OBOT. Patients identified accessibility and privacy as advantages to receiving OBOT in primary care.

Discussion: This research identifies ways providers can provide individualized and effective OUD treatment within the family medicine setting. (J Am Board Fam Med 2020;33:611-615.)

Keywords: Buprenorphine, Opioid-Related Disorders, Patient-Centered Care, Primary Health Care, Treatment Outcome

\section{Introduction}

In 2018, 2 million Americans had an opioid use disorder (OUD), the majority of whom did not receive treatment. $^{1-2}$ Office-Based Opioid Treatment (OBOT) is the delivery of care for OUD with buprenorphine-containing medications or naltrexone within the general medical setting. ${ }^{1}$ Providers often cite time restraints, financial concerns, lack of psychosocial support, and difficult patients as barriers to providing OBOT. ${ }^{3-5}$ Patients who do seek care report lack of affordable options, uncertainty as to where to receive treatment, and fear of negative consequences

This article was externally peer reviewed.

Submitted 24 October 2019; revised 24 February 2020; accepted 26 February 2020.

From University of North Carolina Health Sciences at Mountain Area Health Education Center, Asheville, NC.

Funding: This publication is supported by the Health Resources and Services Administration (HRSA) of the US Department of Health and Human Services (HHS) as part of an award totaling $\$ 1,656,886$ with 0 percent financed with non-governmental sources. The contents are those of the authors and do not necessarily represent the official views of, nor an endorsement, by HRSA, HHS, or the US Government. For more information, please visit HRSA.gov. Conflicts of interest: None.

Corresponding author: Courtenay Gilmore Wilson, PharmD, BCACP, CPP, University of North Carolina Health Sciences at Mountain Area Health Education as barriers to receiving it. $^{2}$ Providing OBOT within family medicine has the potential to address these barriers and increase access to medications for OUD. While the providers' perception of OBOT has been detailed, the patient's experience of OBOT has not been well described. The National Academies of Science calls for research exploring patients' perspectives of treatment models to increase access to individualized, effective OUD care. ${ }^{1}$ Specifically, there is a need to better understand the experience of the patient receiving OBOT in rural areas, which have been particularly affected by the opioid crisis. We aim to build on existing literature by exploring patients' perspectives of OBOT in a rural primary care setting.

\section{Methods}

We are a family medicine residency serving predominately rural Appalachia in a non-Medicaid expansion state. We began providing OBOT in 2015. From July to October 2017, we conducted brief, structured interviews following office visits to explore patients'

Center, 123 Hendersonville Road, Asheville, NC 28803 (Email: Courtenay.wilson@mahec.net). 
perspectives with OBOT. We included patients who had at least 3 office visits where we prescribed buprenorphine-containing medication over at least 1 month. At the time of the study period, there were 57 active patients receiving OBOT. The OBOT scheduler informed eligible patients of the opportunity to participate in an interview following their upcoming visit. The OBOT scheduler confirmed willingness to participate in the postvisit interview when the patient checked-in for their appointment. We interviewed all willing patients consecutively until we achieved 30 interviews. Reasons for nonparticipation included having to reschedule appointments and inability to stay following their OBOT appointment. Given the small size of the program at this time, per our Institutional Review Board, we did not collect demographic information due to the potential to identify individuals. Following verbal consent, 2 members of the research team conducted face-to-face interviews using a standardized interview guide (Appendix 1). Interviews were conducted in a private consulting room that had a couch and space for children to play, if necessary, during the interview. The research team documented answers through written notes and did not audio-record the interview. The interview guide directed the interviewers to ask patients to describe their experiences and opinions related to the clinic's OBOT services, staff, previous experiences with substance use treatment, and other topics related to medications for opioid use disorder and substance use treatment. Participants received \$10 gift cards in recognition of the time they provided.

\section{Data Analysis}

Three authors (CK, CL, CH), with a mix of training in qualitative data analysis, led the thematic data analysis with additional input from the other authors. Thematic analysis can be used to identify, deduce, and report themes that emerge from a data set. $^{6}$ To ensure reliability, we divided all interviews among all authors so that at least 2 authors read and coded each interview. After the initial coding, the research team met to start the iterative process of creating a coding schema through comparing and combining found themes. Through frequent meetings, the team defined and refined themes until every author agreed that the identified themes best represented the data set. The final major themes were decided once they met content saturation among the interview notes and the research team agreed that there was a depth of data to support the findings and themes. The regional Institutional Review Board approved this study.

\section{Results}

Thirty of 57 eligible participants completed interviews. Four factors shaped patients' perspectives of OBOT: societal structures, life before treatment, treatment history, and experiences in OBOT (Figure 1), as exemplified by select participant statements (Table 1). Societal structures were factors outside of participants' control that affected their ability to access OBOT. Participants discussed how these contributed to their instability, shame, and lack of personhood. Life before treatment encompassed factors on the individual level that characterized life with active OUD. Participants juxtaposed the chaos of their life before treatment with the stability they feel while in OBOT. Treatment history pertained to the participant's experiences before receiving care in this setting. Those previously treated with methadone compared that experience to OBOT, both in the delivery of care and the response to the medication. Participants discussed frustrations with the structure of opioid treatment programs (OTPs), especially daily dosing, early morning dosing, lengthy waits, cost, inability to accept Medicaid, and lack of confidentiality. Finally, experiences in this OBOT affected overall perceptions of care. Participants valued our ability to address primary care needs, to accept insurance including Medicaid, and to schedule an appointment throughout the day. They preferred the privacy of treating OUD in a general medical setting. Notably, participants who received treatment at an OTP had positive thoughts on the less intensive OBOT structure, while those who had not received treatment at an OTP found the structure of OBOT demanding. A majority of participants felt their current providers' nonjudgmental approach made it easier to be open about their experiences with recovery. Participants highlighted opportunities to improve care, including greater support in accessing food, housing, and legal services as well as expanded treatment of dental care, chronic pain, mental health, and hepatitis C. They also discussed challenges associated with transitioning from methadone to buprenorphine-containing medications.

When asked what affected their decision to seek care here, 20 of 26 respondents (77\%) agreed it was 
Figure 1. Four factors affecting patients' perspectives of office-based opioid treatment.

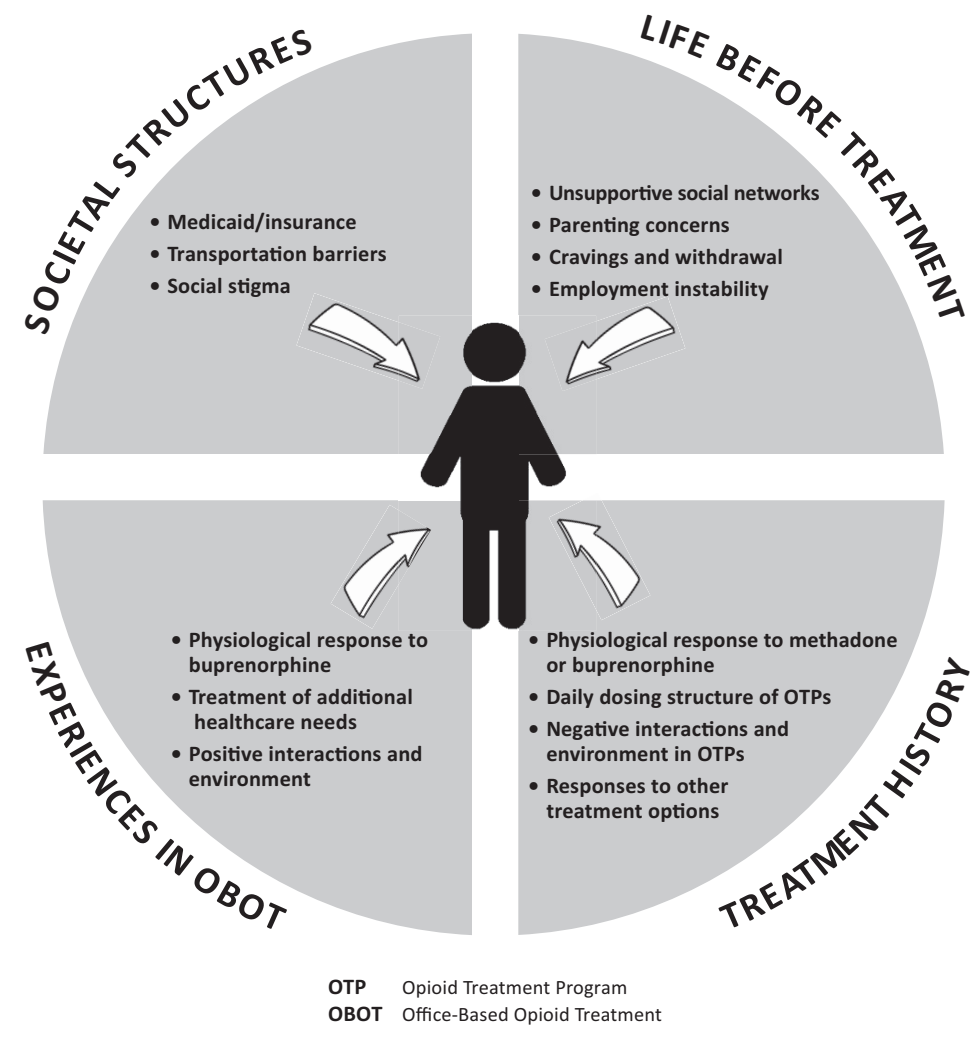

the ability to use insurance, 25 of 27 respondents (93\%) agreed it was the ability to get an appointment, and 23 of 26 respondents (88\%) agreed it was the family medicine setting.

\section{Discussion}

Consistent with prior research, we found provider and societal stigma affected patients' perceptions of their care. ${ }^{7-9}$ In a busy clinic day, it is easy to see only a snapshot of the patient's life. Providers should recognize that the experiences the patient brings to treatment will influence their perception of treatment. In a supportive, affirming way, providers should ask about and address the patient's life before treatment and their treatment history. This is consistent with Fox et $\mathrm{al}^{8}{ }^{8}$ which found patients valued patient-centered models that allowed for self-disclosure of their use.

Care models should limit unnecessary logistic barriers. Participants reflected frustration with the practical implications of strict federal regulations of OTPs. The OTP level of care is necessary for some patients who may need a daily dosing structure or require methadone treatment over other OUD medications. However, OBOT services can provide care for patients who may benefit from a less intensive treatment setting that does not require daily dosing and can address their additional health care needs. Consistent with other findings, patients often value the convenience and privacy of OBOT in the primary care setting. ${ }^{8-9}$ While office-based services cannot meet every patients' treatment needs, OBOT can play an integral role in expanding access to treatment overall, especially in rural communities with limited OTPs such as ours.

Providers should be aware of the social factors that impact their patients' health and advocate for changes in societal structures that affect care when possible. Participant responses highlight the need to improve access to affordable care, remove restrictions on medications for OUD, and address housing and transportation barriers in their community. Our findings are unique in that we provide perspectives from a rural, Medicaid nonexpansion state. This may explain why patients placed significant emphasis on transportation barriers and the need for Medicaid coverage. By understanding the needs of their patients and the barriers they face, providers can connect them to outside resources or 
Table 1. Select Participant Statements Describing the Four Factors That Shape Perspective of Care

\begin{tabular}{|c|c|}
\hline Factors & Participant Statement \\
\hline $\begin{array}{l}\text { Societal } \\
\text { structures }\end{array}$ & $\begin{array}{l}\text { "I'm about to lose Medicaid because I make too } \\
\text { much money [working at McDonalds] and I } \\
\text { will bave to pay for it." } \\
\text { "I have to drive from Tennessee [in order to } \\
\text { receive treatment]." } \\
\text { "The only clinic for treatment in my home town } \\
\text { doesn't accept Medicaid." } \\
\text { "My past is my past, people [including } \\
\text { healthcare providers] tend to look down on } \\
\text { you." }\end{array}$ \\
\hline $\begin{array}{l}\text { Life before } \\
\text { treatment }\end{array}$ & $\begin{array}{l}\text { "I was not in a good place before coming here." } \\
\text { "I was hanging out with people I should not } \\
\text { bave." } \\
\text { "I bad never been addicted to anything before } \\
\text { except smoking.. being addicted to narcotics } \\
\text { made me feel like a bad mother." } \\
\text { "My life is more in control [now]." } \\
\text { "I'm not a borrible person anymore." } \\
\text { "I'm a great person in society instead of a bad } \\
\text { one." }\end{array}$ \\
\hline $\begin{array}{l}\text { Treatment } \\
\text { history }\end{array}$ & $\begin{array}{l}\text { "You can] get more drugs there than anywhere. } \\
\text { You can get anything standing in line at the } \\
\text { clinic." } \\
\text { "Everyone knows your business there, they may } \\
\text { not tell it but they know it." } \\
\text { "Still going to a drug dealer." } \\
\text { "No freedom, no life, they don't care about you." } \\
\text { "Don't have to come every day." [previous care } \\
\text { at Opioid Treatment Program] } \\
\text { "You bave to come often" [no previous } \\
\text { treatment] }\end{array}$ \\
\hline $\begin{array}{l}\text { Experiences in } \\
\text { office-based } \\
\text { opioid } \\
\text { treatment }\end{array}$ & $\begin{array}{l}\text { "If it wasn't for the staff here] I'm not sure } \\
\text { what I would have done." } \\
\text { "[They] make you feel more human here than } \\
\text { other places." } \\
\text { "[I can get care] all in one place." } \\
\text { "Superman cape." } \\
\text { "[I've] woken up." } \\
\text { "It's a world of difference to wake up and feel } \\
\text { good." }\end{array}$ \\
\hline
\end{tabular}

integrate ancillary services into their primary care settings. For example, since the time of this research, our OBOT has aimed to address patients' needs by embedding free legal support and peer support specialists into the clinic. This study is limited in the small sample size. We did not digitally record the interviews; thus, we relied on the accuracy of the interviewers' notes. In addition, we did not offer treatment with extended release naltrexone at the time of this study. Further research is needed to determine patients' preferences between various medications for OUD.

\section{Conclusion}

Family medicine settings can offer patients with nonjudgmental, discrete treatment for OUD. Providers should recognize that the patient's life before treatment, treatment history, and interactions with societal structures will all influence the perceptions of care.

Authors would like to thank Anne Squires and Kara Franke for help with conducting interviews; Brenda Benik for development of the Figure.

To see this article online, please go to: http://jabfm.org/content/ 33/4/611.full.

\section{References}

1. National Academies of Sciences, Engineering, and Medicine. 2019. Medications for opioid use disorder save lives. Washington, DC: The National Academies Press.

2. Substance Abuse and Mental Health Services Administration. 2019. Key substance use and mental health indicators in the United States: Results from the 2018 National Survey on Drug Use and Health (HHS Publication No. PEP19-5068, NSDUH Series H-54). Rockville, MD: Center for Behavioral Health Statistics and Quality, Substance Abuse and Mental Health Services Administration. Retrieved from https://www.samhsa.gov/data/.

3. Andrilla CHA, Coulthard C, Larson EH. Barriers rural physicians face prescribing buprenorphine for opioid use disorder. Ann Fam Med 2017;15: 359-62.

4. Hutchinson E, Catlin M, Andrilla CHA, Baldwin L-M, Rosenblatt RA. Barriers to primary care physicians prescribing buprenorphine. Ann Fam Med 2014;12:128-33.

5. DeFlavio JR, Rolin SA, Nordstrom BR, Kazal LA. Analysis of barriers to adoption of buprenorphine maintenance therapy by family physicians. Rural Remote Health 2015;15:3019.

6. Nowell LS, Norris JM, White DE, Moules N. Thematic analysis: striving to meet trustworthiness criteria. Int J Qual Methods 2017;16:1-13.

7. Hatcher AE, Mendoza S, Hansen H. At the expense of a life: race, class, and the meaning of buprenorphine in pharmaceuticalized "care." Subst Use Misuse 2018;53:301-10.

8. Fox AD, Masyukova M, Cunningham CO. Optimizing psychosocial support during office-based buprenorphine treatment in primary care: Patients' experiences and preferences. Substance Abuse 2016; 37:70-5.

9. McElrath K. Medication-Assisted treatment for opioid addiction in the United States: critique and commentary. Substance Use Misuse 2018;53: 334-43. 


\section{Appendix 1: Interview Guide}

Patient and Provider Experience with Oce

\section{Based Opioid Treatment}

Patient Survey

1. In the past, have you ever received or thought about receiving treatment from an Opioid Treatment Program (OTP)?

IF YES:

a. What was that experience like?

b. How did the staff make you feel? ality?

c. Did you ever have concerns about confidenti-

d. Were the staff there able to help you with other health care needs?

IF NO:

a. Why did you not seek care there?

2. What brought you here?

a. Did the ability to use insurance to pay for the office visits affect your decision to come here?

\section{YES NO NO}

b. Did the ability to get an appointment affect your decision? _ YES _ NO

c. Was the setting (primary care vs substance use clinic) a factor in your decision?

$$
\text { YES _ NO }
$$

3. What has this experience been like for you?

a. Do you feel like your providers here respect you? _ YES _ NO

b. Do you feel listened to? _ YES _ NO here?

c. In your overall experience, do you feel respected

$$
\text { YES _ }
$$

4. What other health concerns do you have that may or may not affect your substance use treatment?

5. Do you feel like your provider addresses your other health care concerns?

V6. Can you tell us about how your life has been since you have been on buprenorphine (Suboxone/ Subutex)? Think about work, family, your overall health and your mood.

a. Are there things in your life that are getting better?

b. Are there things that are worse or not getting better?

7. What would you want the staff to know about your recovery?

a. Are there other services you would want us to provide? [Keep in mind these answers are confidential so we will not be able to address your specific need. But we would love general comments about how to improve our process.]

V8. What do you think other people who are struggling with opioid abuse need to know about this treatment option? What do we need to communicate with patients to get more people into treatment?

V9. Is there anything else you would like to tell us about buprenorphine treatment? 